\title{
Expressions of CCR7 and CXCR4 Are Associated with Differentiation in Gastrointestinal Cancer
}

\author{
Chunhui Lu, Shiwen Chen, Feng Xu, Yiwen Chen, Qing Zhang, Yong Li* \\ Department of Oncology, Gongli Hospital, Shanghai, China. \\ Email: luchunhui@163.com, Chenshiwei1966@hotmail.com, finnxu@foxmail.com, Cinderella198102@hotmail.com, \\ qing.zhang@163.com, ${ }^{*} x$ lliyong@sina.com
}

Received November $28^{\text {th }}, 2012$; revised December $30^{\text {th }}, 2012$; accepted January $9^{\text {th }}, 2013$

\begin{abstract}
Purpose: The chemokine receptors CCR7 and CXCR4 have been shown to play an important role in cancer invasion and metastasis. This study was aimed to investigate CCR7 and CXCR4 expressions and evaluate the association between their expressions and the clinicopathological features in gastrointestinal cancer. Method: 27 paired tissue samples from patients who had curative surgery for gastrointestinal cancer were obtained. Quantitative real-time PCR, immunochemistry assay and western blot analysis were carried out to investigate the expressions of CCR7, CXCR4 expressions in gastrointestinal cancer. Results: The cancer tissues expressed significant higher level of CCR7 $(\mathrm{P}=0.000)$ and CXCR4 $(\mathrm{P}=0.000)$ protein than the adjacent normal mucosa. Expressions of CCR7 $(\mathrm{P}=0.002)$ and CXCR4 $(\mathrm{P}=$ 0.003 ) protein in cancer tissues exhibited significant correlation with differentiation in gastrointestinal cancer. Conclusion: Expressions of CCR7 and CXCR4 protein were associated with differentiation in gastrointestinal cancer. CCR7 and CXCR4 may be predictive factors for poor prognosis in patients with gastrointestinal cancer.
\end{abstract}

Keywords: Chemokine Receptor; CCR7; CXCR4; Gastrointestinal Cancer

\section{Introduction}

Chemokines belong to small-molecule chemoattractive cytokine family and are categorized into four groups (CXC, CC, CX3C, and C) [1-3]. Usually, chemokines are molecules that are structurally and functionally similar to growth factors. They bind to G-protein-coupled receptors on leukocytes and stem cells, and work through guaninenucleotide-binding $(\mathrm{G})$ proteins to initiate intracellular signaling cascades that promote migration towards the chemokine source [1-3].

Chemokine receptors are seven-transmemberane receptors coupled to G-proteins, all with their N-terminus outside the cell surface, three extracellular and three intracellular loops as well as a C-terminus in the cytoplasm. One of the intracellular loops of the chemokine receptors couples with heterotrimeric G-proteins, and that mediate ligand binding to the receptor which initiates signal transduction cascade [4].

To date, at least 20 chemokine receptors (CCR1-11, CXCR1-7, XCR1, and CX3CR1) have been identified. Chemokines and their receptors have been known to play important roles in inflammation, infection, tissue injury, allergy, cardiovascular diseases, and malignant tumors [5].

\footnotetext{
"Corresponding author.
}

Perhaps one of the most important roles that chemokines and the chemokine receptors have is in regulating metastasis. Chemokine receptors may potentially facilitate tumor dissemination at each step of metastasis, including adherence of tumor cells to endothelium, extravasation from blood vessels, metastatic colonization, angiogenesis, proliferation, and protection from the host response via activation of key survival pathways [6,7].

Recent study also indicated that different cancers express varying combinations of $\mathrm{CC}$ and $\mathrm{CXC}$ chemokine receptors. Chemokine receptors may direct lymphatic and hematogenous spread and may additionally influence the sites of metastatic growth of different tumors [8]. The mechanisms involved in lymph node metastasis haven't been fully understood, whereas, more and more evidence has showed a correlation between chemoreceptors CCR7, CXCR4 and various types of malignancy. High expression of CCR7 and CXCR4 are often associated with faster progression and poorer prognosis of the malignant diseases.

In gastrointestinal cancer, Previous studies have showed these two receptors might increase the metastatic phenotype and the risk of poor survival $[9,10]$. However, instead of pure laboratory study on gastro-colorectal cancer cell lines, few reports had focused on the CCR7, CXCR4 expressions in clinical work. Therefore, in this study, we 
investigated CCR7 and CXCR4 expressions in gastrocolorectal tumor specimens to evaluate the association between their expressions and the clinicopathological features of gastrointestinal cancer.

\section{Patients and Methods}

\subsection{Patients Enrollment and Tissue Samples}

This study was approved by the Research Ethics Committee of Gongli Hospital, Shanghai Pudong New Area. China. Written informed consent was obtained from all of the patients enrolled in this study. All specimens were handled and made anonymous according to the ethical and legal standards.

In this study, paired tumour specimens were obtained from 27 patients who underwent radical surgery for gastro-colorectal cancer in our hospital from July to December 2010. The baseline characteristics of enrolled patients were as showed in Table 1. Tumor specimens were obtained at the time of surgery and reserved in pathological laboratory in a $-80^{\circ} \mathrm{C}$ refrigerator. None of the patients had received radiotherapy or chemotherapy prior to surgery.

\subsection{Immunohistochemistry Assay}

Sections of 4-um thickness were obtained from representative central and para-tumor areas of each tumor specimen and were mounted on to glass slides for immunostaining. Briefly, after being sealed in goat serum for 20 minutes the sections were incubated with mouse CCR7 (abcam ${ }^{\circledR}$, ab32527) and CXCR4 (abcam ${ }^{\circledR}$, ab2074) antibody at $4^{\circ} \mathrm{C}$ overnight, then with horseradish peroxidase-labled antimouse immunoglobulin $\left(\mathrm{Sigma}^{\circledR}\right.$, A6154) for 20 minutes, followed by incubation with $0.05 \%$ 3,39-diaminobenzidine tetrahydrochloride solution at $37^{\circ} \mathrm{C}$ for 1 hour. Finally, the slides were counterstained with Mayer's hematoxylin and mounted in an aqueous mounting medium. At each step, the slides were washed carefully in phosphate-buffered saline ( $\mathrm{pH}$ 7.4). The Immunohistochemistry results were divided into 5 grades including negative and positive $(+\sim 4+)$. The results were evaluated by 2 pathologists independently. There was the

Table 1. Baseline characteristics of enrolled patients.

\begin{tabular}{ccccc}
\hline \multirow{2}{*}{} & & \multicolumn{2}{c}{ Clinical grade } & \multirow{2}{*}{ P } \\
\cline { 3 - 4 } & & II (B-C1) & III (C2) & \\
\hline \multirow{4}{*}{ Age } & & $59.47 \pm 9.52$ & $55.63 \pm 14.12$ & 0.414 \\
Gender & Male & 9 & 4 & \multirow{2}{*}{0.983} \\
& Female & 10 & 4 & \\
\multirow{2}{*}{$\begin{array}{c}\text { Differentiation } \\
\text { level }\end{array}$} & Poor & 7 & 4 & \\
& Middle & 7 & 3 & 0.696 \\
& Well & 5 & 1 & \\
\hline
\end{tabular}

additional third pathologist for judgments in case of the former 2 pathologists holding diverse opinion. The following were judgment criteria for immunohistochemistry assay: 1) Cells with buffy cytoplasma were recognized as positive staining; 2) One central and four corner of $10 \times$ 10 visual field of every section would be observed to counting the positive cells for grading; 3 ) The positive cell ratio of $0 \%-20 \%, 20 \%-40 \%, 40 \%-60 \%, 60 \%$ $80 \%$ and $80 \%-100 \%$ was regarded as Grade Negative and Grade $+\sim 4+$ repectively.

\subsection{Western Blot Analysis}

Western blotting was also used to detect CCR7 and CXCR4 protein. The whole specimens were separated into central and para-tumor areas and sonicated respectively. The cells were collected by centrifugation, washed in phosphate-buffered saline (PBS), and lysed by the addition of SDS sample buffer [62.5 mM Tris-HCl (pH 6.8), 6\% (w/v) SDS, 30\% glycerol, $125 \mathrm{mM}$ DTT, and $0.03 \%(\mathrm{w} / \mathrm{v})$ bromophenol blue]. Equal amounts of protein from each sample were electrophoresed on $10 \%$ SDS-polyacrylamide gels and transferred to nitrocellulose membranes. The membranes were blocked for 1 hour with Tris-buffered saline (TBS) containing 5\% (w/v) milk and $0.1 \%$ Tween, and then incubated with the primary antibody CCR7 $\left(\right.$ abcam $^{\circledR}$, ab32527) and CXCR4 $\left(\right.$ abcam $^{\circledR}$, ab2074) overnight at $4^{\circ} \mathrm{C}$. The blots were washed with TBS containing Tween, incubated with horseradish peroxidase-labled antimouse immunoglobulin $\left(\right.$ Sigma $\left.^{\circledR}, \mathrm{A} 6154\right)$ for 1 hour at $37^{\circ} \mathrm{C}$, then add $\mathrm{ECL}$ solution to record the image.

\subsection{Realtime-PCR}

$200 \mathrm{mg}$ separated central or para-tumor sample from each sonicated specimen was weighed to extracting total RNA (Sangon total RNA extracting kit-SK1352, China) for realtime-PCR on PRISM ${ }^{\circledR} 7900 \mathrm{HT}$. Every sample was tested 3 times and the average value was calculated as the results. The primers and fluorescent probes were designed and synthesized by Sangon Biotech (Shanghai) CO. Ltd. PCR was performed under the following conditions: an initial cycle of denaturation at $94^{\circ} \mathrm{C}$ for 2 minutes, followed by $21-23$ cycles of denaturation at $92^{\circ} \mathrm{C}$ for 45 seconds; annealing at $60^{\circ} \mathrm{C}$ for 60 seconds; extension at $72^{\circ} \mathrm{C}$ for 60 seconds; and a final extension at $72^{\circ} \mathrm{C}$ for 5 minutes. The sequences for qRT-PCR primers were as follows:

CCR7 forward, 5'-CTTCTTCAGTGGCATGCTCCTA-3'; reverse, 5'-GCTGAGACAGCCTGGACGAT-3'; CXCR4 forward, 5'-CAGTGGCCGACCTCCTCTT-3'; reverse, 5'-CAGTTTGCCACGGCATCA-3'; GAPDH forward, 5'-CACATGGCCTCCAAGGAGTAAG-3'; reverse, 5'-TGAGGGTCTCTCTCTTCCTCTTGT-3'. 


\subsection{Statistical Analysis}

The quantitative data were measured as average and standard deviation. The association between the variables was tested using the chi-square test or T-test (quantitative data). Probability values of $<0.05$ were considered statistically significant. The statistic analysis was completed with PASW Statistics 18 Software.

\section{Results}

\subsection{CCR7 and CXCR4 Protein Expression in Gastro-Colorectal Cancer}

Of all 27 paired specimens, CCR7 and CXCR4 protein were both detected in central and para tumor tissue by either immunohistochemistry assay (Figure 1) or western blot analysis (Figure 2). The central-tumor tissue expressed significant higher level of CCR7 $\left(\chi^{2}=47.455, \mathrm{P}=\right.$

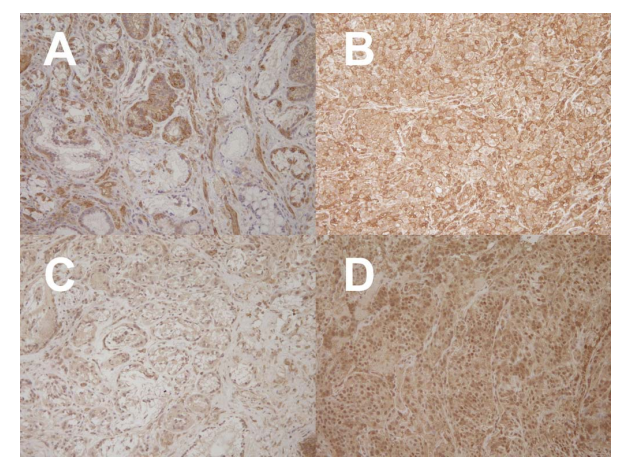

Figure 1. Immunohistochemistry stain of CCR7 and CXCR4 in gastro-colorectal cancer $(\times 200)$. Positive expression of CCR7 in gastro-colorectal cancer with immunostaing (A,B); Positive expression of CXCR4 in gastro- colorectal cancer with immunostaing $(C, D)$.
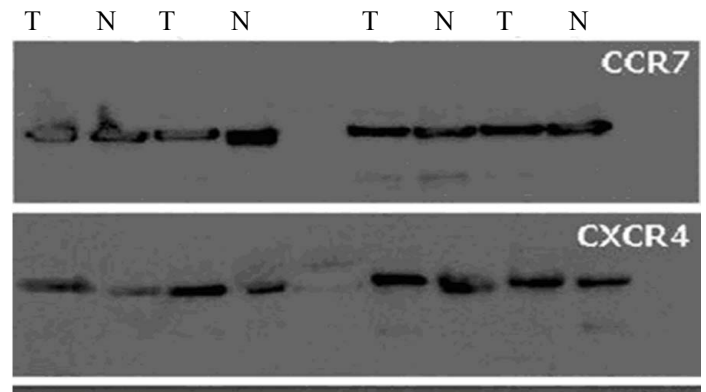

actin

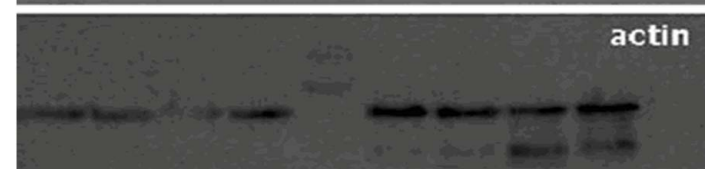

Figure 2. Expression of CCR7 and CXCR4 proteins in gastro-colorectal cancer tissues and adjacent normal mucosa by Western blot analysis. No significance was found between expression of CCR7 and CXCR4 proteins in gastro-colorectal cancer tissues and adjacent normal mucosa. "N" refers to adjacent normal mucosa; " $T$ " refers to gastro-colorectal cancer tissues.
0.000) and CXCR4 $\left(\chi^{2}=47.600, \mathrm{P}=0.000\right)$ protein than para-tumor tissue. However, CCR7 and CXCR4 protein expression between Stages II and III patients showed no variance (Table 2 ).

While comparing patients with various tumor differentiation levels, the CCR7 and CXCR4 protein expression of central tumor samples exhibited significant variance as demonstrated in Table 3.

\subsection{CCR7 and CXCR4 mRNA Expression in Gastro-Colorectal Cancer}

The realtime-PCR showed no mRNA expression difference between central and para tumor tissue for CCR7 $(2.215 \pm 0.462$ vs. $1.962 \pm 0.660, \mathrm{P}=0.109)$ and $\mathrm{CXCR} 4$ $(1.543 \pm 0.836$ vs. $1.483 \pm 1.197, \mathrm{P}=0.832)$. Based on clinical stage and tumor differentiation level, the statistic analysis showed none of them was a factor associated with CCR7 and CXCR4 mRNA expression (Table 4).

\section{Discussion}

This study analyzed the chemokine receptor CCR7, CXCR4 expressions in small series of human gastrocolorectal cancer specimens. Our results showed both CCR7 and CXCR4 protein expressions were significantly higher in cancer tissues than in adjacent normal tissues. Furthermore, CCR7 and CXCR4 protein expressions were significantly lower in better-differentiated tumor. This finding demonstrated that CCR7 and CXCR4 are involved in gastro-colorectal cancer progression just as in many other malignancies, meanwhile the fact that their expressions are associated with tumor differentiation also indicated $\mathrm{CCR} 7$ and $\mathrm{CXCR} 4$ may be predictive factors for faster progression and poorer prognosis of the diseases.

Our study also revealed that the protein and mRNA expressions of CCR7, CXCR4 showed no difference among patients with different stage. This finding does not mean the denial of commonly accepted opinion of the relevance of CCR7, CXCR4 expression with clinical stage in various types of cancer. For example, Schimanski reported that CXCR4 in colorectal cancer was significantly associated with advanced UICC tumor stages [11]. The aim of our study was restrictively confined to candidates who were suitable for radical operation. That means all enrolled patients were stage II or III for gastric cancer and stage Duke's B-C1 or C2 for colorectal cancer and with no distant metastasis. In other words, the tumor progression was at similar level. Theoretically, if surveying a wider stage of the cancer at the time of diagnosis, the results might be different.

The CCR7 and CXCR4 have been considered as possible targets of anti-cancer drugs. Luo has reported that the blockage of CXCR4-SDF1 combination can inhibit 
Table 2. Grading of CCR7 and CXCR4 protein expression between different clinical stage.

\begin{tabular}{|c|c|c|c|c|c|c|c|}
\hline & & \multicolumn{3}{|c|}{ Central-tumor } & \multicolumn{3}{|c|}{ Para-tumor } \\
\hline \multicolumn{2}{|c|}{ Clinical Stage } & II (B-C1) & III (C2) & $\chi^{2}, \mathrm{P}$ & II (B-C1) & III (C2) & $\chi^{2}, \mathrm{P}$ \\
\hline \multirow{4}{*}{ CCR7 } & + & 0 & 0 & \multirow{4}{*}{$\begin{array}{l}1.089 \\
0.580\end{array}$} & $17(62.96 \%)$ & $8(29.63 \%)$ & \multirow{4}{*}{$\begin{array}{l}0.909 \\
0.340\end{array}$} \\
\hline & $2+$ & $6(22.22 \%)$ & $3(11.11 \%)$ & & $2(7.41 \%)$ & 0 & \\
\hline & $3+$ & $7(25.93 \%)$ & $4(14.81 \%)$ & & 0 & 0 & \\
\hline & $4+$ & $6(22.22 \%)$ & $1(3.70 \%)$ & & 0 & 0 & \\
\hline \multirow{4}{*}{ CXCR4 } & + & 0 & 0 & \multirow{4}{*}{$\begin{array}{l}1.052 \\
0.591\end{array}$} & $17(62.96 \%)$ & $8(29.63 \%)$ & \multirow{4}{*}{$\begin{array}{l}0.909 \\
0.340\end{array}$} \\
\hline & $2+$ & $6(22.22 \%)$ & $2(7.41 \%)$ & & $2(7.41 \%)$ & 0 & \\
\hline & $3+$ & $8(29.63 \%)$ & $5(18.52 \%)$ & & 0 & 0 & \\
\hline & $4+$ & $5(18.52 \%)$ & $1(3.70 \%)$ & & 0 & 0 & \\
\hline
\end{tabular}

Table 3. Grading of CCR7 and CXCR4 protein expression among various tumor cell differentiation.

\begin{tabular}{|c|c|c|c|c|c|c|c|c|c|}
\hline & & \multicolumn{4}{|c|}{ Central-tumor } & \multicolumn{4}{|c|}{ Para-tumor } \\
\hline \multicolumn{2}{|c|}{ Differentiation } & Poor & Middle & Well & $\chi^{2}, \mathrm{P}$ & Poor & Middle & Well & $\chi^{2}, \mathrm{P}$ \\
\hline \multirow{4}{*}{ CCR7 } & + & 0 & 0 & 0 & \multirow{4}{*}{$\begin{array}{c}17.025 \\
0.002\end{array}$} & 10 & 9 & 6 & \multirow{4}{*}{$\begin{array}{l}0.623 \\
0.732\end{array}$} \\
\hline & $2+$ & 0 & 5 & 4 & & 1 & 1 & 0 & \\
\hline & $3+$ & 4 & 5 & 2 & & 0 & 0 & 0 & \\
\hline & $4+$ & 7 & 0 & 0 & & 0 & 0 & 0 & \\
\hline \multirow{4}{*}{ CXCR4 } & + & 0 & 0 & 0 & \multirow{4}{*}{$\begin{array}{c}15.709 \\
0.003\end{array}$} & 10 & 9 & 6 & \multirow{4}{*}{$\begin{array}{l}0.623 \\
0.732\end{array}$} \\
\hline & $2+$ & 0 & 4 & 4 & & 1 & 1 & 0 & \\
\hline & $3+$ & 5 & 6 & 2 & & 0 & 0 & 0 & \\
\hline & $4+$ & 6 & 0 & 0 & & 0 & 0 & 0 & \\
\hline
\end{tabular}

Table 4. CCR7, CXCR4 mRNA expression based on clinical stage and differentiation level.

\begin{tabular}{|c|c|c|c|c|c|}
\hline & & \multicolumn{3}{|c|}{ Clinical stage } & \multirow{2}{*}{$\chi^{2}, P$} \\
\hline & & II (B-C1) & & III (C2) & \\
\hline \multirow{2}{*}{ CCR7 } & central & $2.171 \pm 0.484$ & & $2.319 \pm 0.417$ & $0.228,0.633$ \\
\hline & para & $1.939 \pm 0.748$ & & $2.017 \pm 0.417$ & $0.477,0.490$ \\
\hline \multirow{2}{*}{ CXCR4 } & central & $1.537 \pm 0.920$ & & $1.558 \pm 0.648$ & $0.282,0.595$ \\
\hline & para & $1.669 \pm 1.377$ & & $1.042 \pm 0.363$ & $3.454,0.063$ \\
\hline & & \multicolumn{3}{|c|}{ Differentiation level } & \\
\hline & & Poor & middle & well & $\chi, P$ \\
\hline \multirow{2}{*}{ CCR7 } & central & $2.158 \pm 0.593$ & $2.155 \pm 0.273$ & $2.419 \pm 0.458$ & $1.137,0.566$ \\
\hline & para & $1.806 \pm 0.442$ & $1.990 \pm 0.821$ & $2.200 \pm 0.733$ & $1.673,0.433$ \\
\hline \multirow{2}{*}{ CXCR4 } & central & $1.769 \pm 1.127$ & $1.324 \pm 0.551$ & $1.494 \pm 0.579$ & $0.623,0.732$ \\
\hline & para & $1.585 \pm 1.711$ & $1.207 \pm 0.544$ & $1.757 \pm 0.891$ & $2.019,0.364$ \\
\hline
\end{tabular}

tumor cell growth and metastasis [12]. Our study found the deviation in expression of CCR7 and CXCR4 at protein level did not exhibit at mRNA level as well among various differentiation cancers. This phenomenon indicated that the difference in translation of mRNA might be a key step for the variant expression of CCR7 and 
CXCR4. For anti-cancer therapy, inhibiting the translation of CCR7, CXCR4 mRNA may be another effective approach.

\section{REFERENCES}

[1] M. Baggiolini, B. Dewald and B. Moser, "Human Chemokines: An Update," Annual Review of Immunology, Vol. 15, 1997, pp. 675-705. doi:10.1146/annurev.immunol.15.1.675

[2] B. J. Rollins, "Chemokines,” Blood, Vol. 90, No. 3, 1997, pp. 909-928.

[3] G. S. Kelner, J. Kennedy, K. B. Bacon, et al., "Lymphotactin: A Cytokine That Represents a New Class of Chemokines," Science, Vol. 266, No. 5189, 1994, pp. 13951399. doi:10.1126/science. 7973732

[4] R. M. Ransohoff, "Chemokines and Chemokine Receptors: Standing at the Crossroads of Immunobiology and Neurobiology," Immunity, Vol. 31, No. 5, 2009, pp. 711721. doi:10.1016/i.immuni.2009.09.010

[5] A. Rot and U. H. von Andrian, "Chemokines in Innate and Adaptive Host Defense: Basic Chemokinese Grammar for Immune Cells," Annual Review of Immunology, Vol. 22, No. 1, 2004, pp. 891-928. doi:10.1146/annurev.immunol.22.012703.104543

[6] G. Lazennec and A. Richmond, "Chemokines and Chemokine Receptors: New Insights into Cancer-Related Inflammation," Trends in Molecular Medicine, Vol. 16, No. 3, pp. 133-144. doi:10.1016/j.molmed.2010.01.003
[7] R. C. Kruizinga, J. Bestebroer, P. Berghuis, C. J. de Haas, T. P. Links, E. G. de Vries, et al., "Role of Chemokines and Their Receptors in Cancer," Current Pharmaceutical Design, Vol. 15, No. 29, 2009, pp. 3396-3416. doi:10.2174/138161209789105081

[8] A. Zlotnik, "Chemokines and Cancer," International Journal of Cancer, Vol. 119, No. 9, 2006, pp. 2026-2029. doi: $10.1002 /$ ijc. 22024

[9] J. Kim, H. Takeuchi, S. T. Lam, R. R. Turner, H. J. Wang, C. Kuo, L. Foshag, A. J. Bilchik and D. S. Hoon, "Chemokine Receptor CXCR4 Expression in Colorectal Cancer Patients Increases the Risk for Recurrence and for Poor Survival," Journal of Clinical Oncology, Vol. 23, No. 12, 2005, pp. 2744-2753. doi:10.1200/JCO.2005.07.078

[10] C. C. Schimanski, P. R. Galle and M. Markus, "Chemokine Receptor CXCR4-Prognostic Factor for Gastrointestinal Tumors," World Journal of Gastroenterology, Vol. 14, No. 30, 2008, pp. 4721-4724.

[11] C. C. Schimanski, S. Schwald, N. Simiantonaki, C. Jayasinghe, U. Gonner, V. Wilsberg, T. Junginger, M. R. Berger, P. R. Galle and M. Moehler, "Effect of Chemokine Receptors CXCR4 and CCR7 on the Metastatic Behavior of Human Colorectal Cancer," Clinical Cancer Research, Vol. 11, No. 5, 2005, pp. 1743-1750. doi:10.1158/1078-0432.CCR-04-1195

[12] Y. Lou, J. Cai, H. Xue, et al., "Functional SDF1 Alpha/CXCR4 Signaling in the Developing Spinal Cord," Journal of Neurochemistry, Vol. 93, No. 2, 2005, pp. 452-462. doi:10.1111/j.1471-4159.2005.03049.x 